DOI: 10.12957/demetra.2015.15996

\title{
"Cozinhar é alimentar as futuras gerações": estudo antropológico sobre a culinária trentino-tirolesa do bairro de Santa Olímpia, Piracicaba-SP
}

\section{"Cooking is to feed the future generations": anthropological study of the Trentino Tyrolean cuisine in the neighborhood of Santa Olympia, Piracicaba-SP, Brazil}

Fernando Monteiro Camargo'

${ }^{1}$ Universidade Federal de São Paulo. Programa de Pós-Graduação em Ciências Sociais, Departamento de Ciências Sociais, Escola de Filosofia Letras e Ciências Humanas.

Correspondência / Correspondence Fernando Monteiro Camargo E-mail:camargo.fmc@gmail.com

\section{Resumo}

Santa Olímpia é um bairro de imigrantes trentino-tiroleses localizado na cidade de Piracicaba, interior do Estado de São Paulo. Este artigo é uma reflexão realizada a partir de pesquisa encomendada pela associação do bairro, com levantamento e documentação da culinária local, nos anos 2012, 2013 e 2014. O intuito era registrar, em forma de livro, as receitas tirolesas de Santa Olímpia. O processo de pesquisa caracterizou-se por duas etapas. Na primeira, acompanhou-se o processo de confecção das receitas com moradoras do bairro com idades entre 40 e 60 anos. Na segunda, o autor participou de encontros com grupos de mulheres com mais de 60 anos, para conversar sobre as receitas. A proposta deste artigo é mostrar como o processo de construção do livro de receitas despertou a narrativa da memória social do bairro. Mais especificamente, é refletir sobre como emoções, significados, relações sociais e a identidade coletiva de um bairro podem se manifestar a partir de narrativas construídas em rodas de conversas sobre o fazer culinário trentino-tirolês de Santa Olímpia. Durante todo o processo, foi possível refletir sobre os significados desta culinária que alimenta as novas gerações. As receitas do bairro contam histórias.

Palavras-chave: Antropologia. Alimentação. Culinária. Memória.

\section{Abstract}

Santa Olímpia is a Trentino Tyrolean immigrant neighborhood in the city of Piracicaba, State of São Paulo, Brazil. This article is a reflection based on a research work ordered by the neighborhood's 
association, with a survey and the documentation of the local cuisine. The research was conducted in years 2012, 2013, and 2014, aiming to record the Tyrolean recipes of Santa Olímpia in book form. The research process involved two stages. The first comprised the making of recipes with the female neighborhood residents aged 40-60 years old. In the second moment, the author attended meetings of groups of women with more than 60 years to talk about the recipes. So this paper aims to show how the process of producing a cookbook aroused the narrative of the neighborhood's social history. More specifically, to reflect how emotions, meanings, social relations and the collective identity of a neighborhood can manifest from narratives that emerged in groups talking about the making of Trentino Tyrolean food in Santa Olympia. The neighborhood's recipes tell stories.

Key words: Anthropology. Food. Cooking. Memory.

\section{Introdução}

Olhar para as temporalidades que habitam a memória de um povo e para os processos de mudanças sociais e culturais a partir dos hábitos alimentares revela como as sociedades concebem seus modos de vida e definem a identidade social de seus membros. A memória e a reflexão dos processos de registro e documentação da culinária de um lugar podem ser aspecto interessante para o conhecimento antropológico, uma vez que esses processos despertam sentimentos, emoções, significados e transformações no cotidiano dos agrupamentos humanos.

Este artigo é fruto de um estudo antropológico sobre a culinária de Santa Olímpia, pequeno bairro de imigrantes trentino-tiroleses localizado na cidade de Piracicaba, no interior do Estado de São Paulo. São apresentadas, aqui, reflexões a partir de pesquisa encomendada para a produção de um livro de receitas. A proposta é mostrar como o processo de construção do livro despertou a narrativa da memória social do bairro. Mais especificamente, o objetivo é refletir sobre como emoções, significados, relações sociais e a identidade coletiva de um bairro podem se manifestar a partir de narrativas construídas em rodas de conversas sobre o fazer culinário trentino-tirolês de Santa Olímpia. A partir dessas rodas de conversas, foi possível compreender como os moradores de Santa Olímpia (re)constroem suas histórias e memórias por meio de sua culinária. Tendo como referencial a antropologia da alimentação, procura-se responder, o quê, quando, como, onde e com quem ${ }^{1}$ se come nas famílias durante a realização desta pesquisa. 


\begin{abstract}
Segundo Roberto Da Matta, ${ }^{2}$
Alimento é algo universal e geral. Algo que diz respeito a todos os seres humanos: amigos ou inimigos, gente de perto e de longe, da rua ou de casa, do céu e da terra. Mas a comida é algo que define um domínio e põe as coisas em foco. Assim, a comida é correspondente ao famoso e antigo de-comer, expressão equivalente a refeição, como de resto é a palavra comida. Por outro lado, comida se refere a algo costumeiro e sadio, alguma coisa que ajuda a estabelecer uma identidade, definindo, por isso mesmo, um grupo, classe ou pessoa.
\end{abstract}

\title{
Do livro de receitas à pesquisa antropológica
}

A pesquisa foi uma iniciativa da diretoria do Circolo Trentino de Santa Olímpia," que tinha como proposta fazer um levantamento sobre a culinária existente no bairro e organizá-la em forma de livro de receitas.* No início de 2012, o autor foi convidado a desenvolver a pesquisa; aceitou o desafio por acreditar que poderia colaborar com a transmissão desse saber para as gerações futuras e contribuir para valorizar a cultura local. O trabalho foi muito prazeroso, pois, além de experimentar todas as receitas, houve a oportunidade de conhecer de perto ricas histórias, sentimentos e memórias presentes na culinária tirolesa.

A comida no bairro de Santa Olímpia é um vetor de comunicação que atua e aproxima diferentes temporalidades. Em volta de uma mesa, no quintal da casa de Dona Negri**** (60 anos), as dificuldades da alimentação enfrentadas no passado são lembradas e contadas com a fartura do presente. Segundo Maciel \& Castro, ${ }^{3}$ Lévi-Strauss, em Mitológicas (1964), utiliza a análise do preparo dos alimentos para estudar os mitos indígenas. Ao fazer isto

Lévi-Strauss nos demonstrou que os alimentos podem ser utilizados quando se busca entender melhor aquilo que nos faz humanos. [...] Lévi-Strauss nos instiga a pensar a comida a partir de sua função semiótica e comunicativa. Para ele, a cozinha é uma linguagem, uma forma de comunicação, um código complexo que permite compreender os mecanismos da sociedade à qual pertence, da qual emerge e que lhe dá sentido.

Dessa forma, o artigo procura explorar o ato de comer "não apenas considerando sua função biológica, mas também sua inserção numa dada cultura ou sociedade”. ${ }^{3}$ Para Claude Fischler, ${ }^{4}$ ao se alimentar, "o homem nutre-se de nutrientes, mas também de imaginários que são partilhados

* Os círculos trentinos são entidades formadas pelos descendentes de trentino-tiroleses do mundo inteiro, que trabalham na preservação de sua cultura por meio da promoção de diversas atividades civis e culturais.

** O Circolo Trentino de Santa Olímpia firmou, em 2015, parceria com o Instituto de Pesquisas e Planejamento de Piracicaba, para publicação do livro de receitas do bairro de Santa Olímpia.

*** Todos os nomes utilizados neste artigo são fictícios. 
socialmente". Em Santa Olímpia, a comida "típica" movimenta não só o cotidiano, mas também as festas do bairro.

Os ritos, assim, ao mesmo tempo em que alteram e estabelecem cortes no fluxo cotidiano, não constituem momentos essencialmente diferentes da rotina diária, uma vez que, neles, determinados aspectos desse mesmo cotidiano são salientados, colocados em foco. ${ }^{5}$

Olhar para as escolhas do que é e pode ser comido no cotidiano e do que é e pode ser servido nas festas do bairro é ver como os tiroleses criam suas relações com os de dentro e como querem ser vistos pelos de fora.

\section{Santa Olímpia}

Santa Olímpia é um bairro de imigrantes trentino-tiroleses ${ }^{* * * *}$ localizado na área rural de Piracicaba-SP. Situado aproximadamente a vinte quilômetros do centro comercial da cidade, às margens da rodovia Piracicaba-Charqueada (SP-308), seu processo de fundação iniciou-se em 1881, ano em que famílias trentino-tirolesas imigraram para o interior de São Paulo para trabalhar na fazenda de café Sete Quedas, ${ }^{* * * * *}$ de propriedade do Sr. Visconde de Indaiatuba. Em 1892, os imigrantes foram transferidos para a fazenda Monte Alegre, localizada em Piracicaba, o que deu início ao processo de fundação do bairro de Santa Olímpia. O bairro, atualmente, é um núcleo de colonização trentino-tirolesa e, por meio do Circolo Trentino di Santa Olímpia, está interligado aos demais círculos trentinos do mundo. Diversas atividades culturais são promovidas lá, como por exemplo, um grupo folclórico com mais de cem integrantes, três corais, grupos de teatro e de danças típicas e pequenas bandas musicais. Além disso, em Santa Olímpia, são promovidas aulas do dialeto local e festas tradicionais ligadas à culinária do bairro. ${ }^{6}$

\section{Por que a culinária do bairro?}

A primeira etapa da pesquisa constituiu de conversas informais realizadas com moradores do bairro ligados por grau de parentesco (mãe, avó, tia, prima etc.) com membros da diretoria do

\footnotetext{
**** A região da província autônoma de Trento está localizada no extremo norte da Itália. Politicamente, está unida à província autônoma de Bolzano (Bozen), atualmente chamada região Trentino-Alto Adige. Trata-se da porção meridional do antigo Tirol do Sul, até 1918 unido ao Tirol austríaco. Sua principal característica é que a língua do trentino é, historicamente, a italiana, enquanto a das demais regiões é a alemã.

***** Atualmente, a fazenda Sete Quedas é parte do território da cidade de Campinas.
} 
Circolo Trentino de Santa Olímpia. A maioria dessas conversas foi com mulheres de 40 a 60 anos de idade. Delas emergiram as primeiras receitas transcritas no processo de registro.

Ao saberem que se buscavam informações sobre a culinária trentino-tirolesa das famílias do bairro de Santa Olímpia, as interlocutoras ficaram surpresas. Queriam saber por que o autor não estava interessado na dança típica e no dialeto local, para elas, algo muito mais ligado a suas tradições. Ficaram admiradas com o fato de o interesse ser justamente a cozinha, na qual, segundo elas, "não existiam segredos". Essa primeira etapa foi fundamental, pois, a partir dessas mulheres, estabeleceu-se um contato mais próximo com outras, conhecidas por todos como "detentoras" do saber culinário, as nonnas. Essa primeira etapa de conversas sempre foi realizada na casa da Dona Negri (60 anos), mãe de um membro da diretoria do Circolo Trentino de Santa Olímpia.

Durante sete sábados, no período da tarde, foram realizadas reuniões no quintal de Dona Negri, com o intuito de fotografar pratos típicos da culinária do bairro. O grupo variava entre 10 a 15 pessoas, que passavam a tarde conversando sobre a culinária "típica" do bairro, enquanto Dona Negri elaborava os pratos na cozinha com porta para o quintal.

Na cozinha, Dona Negri prepara a polenta. É possível observar da porta e logo o autor é convidado a participar: "Quer mexer? Pega aqui e não para de mexer". Mexendo a panela para não deixar a polenta grudar, é perguntado a Dona Negri o que significa para ela participar da pesquisa de registro da culinária do bairro. Ela responde: "Acho bom; acho que precisa pôr no papel isso que a gente sabe, porque, meu filho, cozinhar aqui é alimentar as futuras gerações".

Ao cozinhar para alimentar as futuras gerações, Dona Negri não apenas alimenta e nutre seus filhos e netos do ponto de vista fisiológico; a seleção dos ingredientes, o modo de preparar a comida e as histórias contadas em volta da mesa alimentam certa forma de viver tirolesa.

Se é possível avaliar o valor nutritivo do alimento (um combustivel a ser liberado como energia e sustentar o corpo) o ato de alimentar implica também em um valor simbólico, o que complexifica a questão, pois requer um outro tipo de abordagem. ${ }^{7}$

As conversas no quintal e na cozinha continuam... É gente entrando e saindo da cozinha o tempo todo; cada um dá seu palpite sobre a polenta que está sendo feita; cada pessoa se lembra de um jeito diferente de sua mãe preparar a polenta e, dessa forma, vão surgindo outras histórias. Dona Correr (45 anos) lembra-se de que antigamente as rodas de conversas eram compartilhadas em volta do fogão à lenha: "A gente ficava todo mundo em volta do fogão... aquele ali mesmo no canto do quintal; agora serve para entulhar coisas em cima. Esse aí nem é tão bonito. Tem um lá na casa da minha mãe que é lindo.Seria até bom para você fotografar". 
O fogão a gás substituiu o fogão à lenha, mas as histórias compartilhadas entre elas trazem o passado rico ao presente. A proposta era preparar o prato tradicional para fotografar, mas quantas imagens surgem das vozes dessas senhoras: ora a dureza no plantar, colher e moer o fubá, ora a traquinagem de roubar a linguiça pendurada pela mãe em cima do fogão, ou o "roubo" do pedaço da mortadela que a mãe mandava comprar na venda. E as coças, surras que levavam quando desobedeciam? Quantas risadas despertam hoje as malvadezas que faziam com os meninos menores. $\mathrm{O}$ cheiro gostoso do alimento mistura-se às histórias e risadas da cozinheira e de todos aqueles que por ali chegam. A comida fala, conta histórias!

Quando eu era pequena, não tinha nenhuma venda aqui no bairro, então tínhamos que ir à venda que tinha lá na cidade. A minha mãe falava, vai buscar mortadela lá na venda menina. Eu ia, mas no meio do caminho já tinha comido metade da mortadela. Era longe menino e, no caminho tinha fome! (Dona Stênico, 55 anos).

\section{As nonnas e seus segredos}

Em um segundo momento de pesquisa, foram organizadas rodas de conversas com as moradoras mais velhas do bairro. Essas reuniões aconteceram em um casarão antigo, sede da Associação dos Moradores do Bairro, adquirido para futuramente abrigar um museu. Dessas rodas de conversas surgiram mais de vinte receitas da culinária trentino-tirolesa (entre doces e salgados). As protagonistas dessa fase da pesquisa são mulheres com idades acima de 65 anos para os tiroleses mais jovens, as nonnas. Elas escolheram o que lhes era mais familiar, a comida, para transmitir por gerações as tradições de Santa Olímpia. Para as nonnas, o ritual em volta da mesa é repleto de simbolismos que as fazem reviver o passado, demonstrando a superação dos dias difíceis causados pelo processo migratório. Os pratos são muitos, mas predomina o uso da farinha de milho em vários deles, utilizada para fazer a polenta. Nas palavras de uma das nonnas:

polenta... polenta assada ... ou polenta assim... a gente fazia polenta e depois punha com queijo... com ovo... com linguiça... comia todo dia... com leite... torrava na chapa e comia com leite... polenta com leite é uma delícia. (Dona Popermayer, 87 anos).

Em Santa Olímpia, o que marca a alimentação do cotidiano do bairro, constituindo-se na comida básica, é a polenta, uma comida feita com fubá, água, óleo e temperos, que aparece tanto como prato principal quanto como acompanhamento de outros pratos. A polenta está presente em pelo menos uma das refeições do dia, no café da manhã, no almoço ou no jantar. No café da manhã, é geralmente comida na chapa, com leite. Já no almoço e no jantar, a forma como é servida varia mais: polenta mole, assada, na chapa com queijo ou frita. 
A base para fazer a polenta é o fubá, e seu uso acompanha toda a história de formação do bairro de Santa Olímpia. Antigamente, a utilização do fubá como base alimentar para a culinária tirolesa deu-se em virtude de diversos fatores. Dentre eles, o alto preço da farinha de trigo e a facilidade do cultivo do milho e seu processamento na região.

Antigamente, o milho era plantado por todas as famílias do bairro e era trocado por fubá nos dois moinhos, construídos também por imigrantes tiroleses. Com o passar do tempo, os dois moinhos foram desativados. No entanto, a utilização desse ingrediente como base alimentar da culinária trento-tirolesa permaneceu, permitindo a constituição da tradição no bairro.

O fubá e, consequentemente, a polenta, tornou-se um marco identitário da culinária, processo lento, em que os moradores passaram a dar sentido simbólico a algo que faziam por necessidade de sobrevivência. Os hábitos alimentares apresentados como uma tradição possibilitam despertar lembranças por meio das quais os moradores podem se orientar e distinguir, expressando determinado modo e estilo de vida.

Das lembranças vividas surgem outras mais antigas, contadas por gerações distantes, e no vai e vem das conversas conhecemos a vida no passado.

Dizem que o fubá, antigamente, era feito no pilão, mas desse tempo eu não me lembro. Lembro bem do moinho... tinha dois... um em Santana, o dos Negri. A gente levava o milho lá no moinho e trocava por fubá. Hoje em dia, a gente usa tudo fubá comprado, né? É bem diferente... antigamente o fubá era melhor. (Dona Degaspari, 78 anos).

Ao contar as histórias no antigo casarão, as nonnas dão voz às receitas, que, por sua vez, falam dos encontros, emoções e transformações do bairro de Santa Olímpia. Essas receitas sobreviveram ao tempo na memória dos moradores, sem nunca serem escritas ou documentadas. O desafio de registrar as receitas foi transformar esse saber culinário em medidas e modos de preparo, além de traduzir a arte dos temperos e segredos dessa cozinha. Esse esforço permitiu compreender a culinária tirolesa em seu aspecto simbólico, proporcionando sua inteligibilidade em outros contextos.

No casarão antigo, foram organizadas seis rodas de conversas com as nonnas. Em seis terçasfeiras, às 19 horas da noite, depois da missa, encontrei-me com as moradoras mais antigas do bairro. No primeiro encontro, foram cinco nonnas levadas por suas filhas. Desconfiadas, não sabiam muito bem o que iam fazer ali. Acharam estranho irem até o antigo casarão para conversar sobre a culinária, uma vez que esse casarão guarda objetos, quadros e informações sobre a vida de antigamente em Santa Olímpia. As filhas participaram dessas rodas e contribuíram muito para que as conversas fluíssem. Todos se sentaram ao redor de uma mesa grande do casarão, sob o retrato dos fundadores de Santa Olímpia na parede, e começaram a falar das receitas tirolesas. Falavam dos ingredientes, mas se perdiam nas quantidades, pois havia divergências que levantavam discussões 
intermináveis entre elas. Recorriam às lembranças do passado para definir as quantidades exatas, e concluíam falando que "tinha quer ser no olho, não tem quantidade certa, cada uma faz de um jeito". Suas filhas insistiam para que elas fossem precisas na quantidade para que o livro de receitas ficasse "correto".

Com o passar dos encontros, o grupo foi crescendo, chegando a reunir 18 nonnas no último. Todas iam animadas para falar de suas receitas e de suas lembranças. Muitas vezes, conversavam entre si em dialeto local para que o pesquisador não entendesse - que ficava imaginando se era algum segredo culinário ou algum comentário em relação a ele.

As memórias das nonnas vão fluindo e, aos poucos, as lembranças das comidas vão revelando outras histórias que marcaram a trajetória dos moradores no bairro. "Naquele tempo era tudo mais difícil; não tinha, assim, mistura todo dia, então a gente tinha que aproveitar tudo... inventar a comida com o que tinha" (Dona Vitti, 73 anos).

\section{Das dificuldades do passado à fartura do presente}

Conversando com a nonnas sobre as condições de vida dos primeiros moradores do local, percebeu-se que antigamente a vida no bairro de Santa Olímpia era muito difícil; as famílias eram sempre numerosas: os casais chegavam a ter 14 filhos. O bairro, distante da área urbana, ficava ainda mais isolado da cidade. Os maridos saíam para trabalhar na lavoura e só voltavam no final do dia. A responsabilidade da casa e dos filhos ficava com as mulheres, que tinham que se desdobrar e inventar receitas para satisfazer a todos. A necessidade de aproveitar tudo o que era produzido, aliada aos saberes culinários provenientes do trentino, fez com que essas mulheres criassem novos pratos "com um jeito trentino-tirolês de cozinhar".

Então eu que cozinhava ... ai meu Deus, quando era hora de fazer a... marmita pra ele... era duro, né... porque não tinha as coisas para fazer e a gente tinha de inventar, então era difícil. (Dona Altmeyer, 82 anos).

Antigamente, três festas eram realizadas durante o ano: uma em maio, outra em dezembro e a Festa della Cucagna - na terça-feira de Carnaval. Esses eram os momentos de confraternização, alegria e de certa fartura em Santa Olímpia.

Atualmente, ao chegar ao bairro de Santa Olímpia, nos deparamos com um ambiente de fartura e alegria, no qual não há miséria, diferente do cenário revelado nos depoimentos dos mais antigos moradores. A cucagna, prato típico tirolês, feito de um mexido de ovos, linguiça e polenta, representa êxtase, fartura e muita alegria; é um símbolo da sensação que se tem hoje ao entrar no bairro. A tradição de comer a cucagna na terça-feira de Carnaval ainda permanece. No entanto, 
durante o ano todo são promovidas festas em que a fartura e a comida reinam, demonstrando que as dificuldades enfrentadas no passado foram superadas.

Por meio de receitas transmitidas de geração em geração, Santa Olímpia constrói-se como tradição trentino-tirolesa, unindo seus moradores em um grupo que partilha códigos sociais que operam nas relações locais.

[...] depois desfiava... linguiça bem petiqueninha fritava junto... queijo... ovo... tomate... e ovo batido... e comia com polenta. (Dona Altmeyer, 82 anos).

Esses depoimentos permitiram compreender como a vida social em Santa Olímpia toma forma a partir do entendimento do lugar que a culinária ocupa na dinâmica das relações sociais dos moradores.

"Comer polenta faz eu lembrar da vida de antigamente" - essa fala de uma nona, moradora do bairro, revela a importância do alimento para além da sobrevivência biológica da espécie humana. $\mathrm{O}$ ato de alimentar-se envolve um sistema simbólico de representações, escolhas e classificações que organizam visões de mundo. A cozinha, entendida como vetor de comunicação, possibilita compreender os mecanismos pelos quais a identidade do bairro de Santa Olímpia emerge e que lhe dão sentido. Denise Amon \& Renata Menasche ${ }^{8}$ já falaram sobre a relação entre comida e memória e mostraram que a comida tem uma dimensão comunicativa como a fala e, portanto, pode-se, a partir dela, contar histórias.

As duas principais festas de Santa Olímpia possuem nomes de comidas: Festa da Polenta e a Festa della Cucagna.

A Festa da Polenta de Piracicaba acontece desde 1992 e é promovida pelos moradores do bairro Santa Olímpia com a intenção de comemorar a imigração trentina para a cidade. A primeira edição da festa, em 1992, teve o intuito de festejar o centenário dessa imigração. Em 1993, a festa foi repetida, mas somente em 1999 teve sua terceira edição realizada. De lá para cá, a festa ocorre todos os anos, no mês de julho, tendo completado seu 16º aniversário em 2012.

A festa reúne aproximadamente 15 mil visitantes, que têm à disposição comidas típicas trentinas, tais como, polenta con crauti (polenta acompanhada de chucrute, speck e linguiça), canederle ou knödel (nhoques de pão com linguiça e especiarias, servidos em uma sopa de frango), a polenta con cuccagna (fritada de ovos com tomates, linguiça, bacon e queijo), o strangola pretti (nhoques verdes), polenta frita, salsichão, gròstoi (pasteizinhos doces); tudo isso acompanhado por cerveja ou vinhos de uva e de laranja, além do destilado de casca de uva, a grappa, todos de fabricação local. Essas comidas e bebidas são servidas em três espaços diferentes: tendas montadas na rua, salão de festas e bares adaptados. É montada, também, uma cafeteria no porão do casarão sede 
da associação, em que é servido, além do cafezinho, chocolate quente, cappuccino, bolos e doces produzidos pelos moradores de Santa Olímpia. Segundo Maria Eunice Maciel,

[...] a comida pode marcar um território, um lugar, servindo como marcador de identidade ligado à uma rede de significados. Podemos assim falar em "cozinhas" de um ponto de vista "territorial", associadas a uma nação, território ou região, [...] indicando locais de ocorrência de sistemas alimentares delimitados. ${ }^{7}$

Além das comidas e bebidas, danças típicas, apresentações de corais e bandas de músicas tirolesas fazem parte da programação oficial. Missas são promovidas após cada festejo, ocupando lugar especial como celebração, manifestação da fé religiosa cujo ritual põe a comunidade em comunicação com Deus. Todas as atividades da festa, desde a preparação, são realizadas pelos moradores do bairro, que obedecem a uma escala de horários/atividades.

A Festa da Polenta é, portanto, uma apresentação do bairro para turistas. É a forma com que se arrecada dinheiro para efetuar melhorias de infraestrutura. Mostrar a tradição para quem é de fora é o foco da festa, por isso muitos moradores, durante o evento, usam trajes típicos e aproveitam para praticar mais o dialeto.

Para Maria Eunice Maciel, ${ }^{7}$ a constituição de uma cozinha típica vai mais longe que uma lista de pratos, mas implica práticas associadas ao pertencimento. Nem sempre o prato considerado "típico", aquele que é selecionado e escolhido para ser o emblema alimentar da região, é o de uso mais cotidiano. Ele pode, sim, representar o modo pelo qual as pessoas querem ser vistas e reconhecidas. $^{7}$

Na terça-feira de Carnaval, ocorre a mais antiga festa promovida no bairro de Santa Olímpia, a Festa della Cuccagna. Cuccagna é uma expressão presente no dialeto trentino para indicar estado de êxtase, onde há fartura, onde não há miséria, mas muita alegria, além de ser nome de um prato típico.

A festa tem início às 11 horas da manhã com uma caminhada dos moradores pelo bairro. Lambuzados de lama, caminhando pelas ruas, atravessando terrenos e até um riacho, a caravana segue sempre cantando. O lema é não ficar limpo. Essa manifestação estende-se até as 17 horas, quando então é servida a polenta acompanhada da cuccagna, servidas gratuitamente aos presentes. Após a refeição, tem início o baile de Carnaval na praça central de Santa Olímpia, que segue até a meia-noite, quando é interrompida em respeito ao período da Quaresma, que se inicia, sinal do apego às tradições da Igreja Católica.

Antigamente a gente se pintava de preto... usava as panelas pretas, né? ... um dia fui buscar água, porque não tinha água encanada. Era um dia de Carnaval; eles me pegaram, me colocaram no chão e esfregavam as caçarolas no rosto. Ai meu Deus... me deixaram toda preta. Agora eles fazem isso com o barro, né? (Dona Forti, 81 anos) 
Ao dar às duas principais festas do bairro nomes de comidas típicas tirolesas, os moradores utilizam a culinária como símbolo de uma identidade reivindicada, da qual o modo de vida tornase particular, singular e reconhecível. Essa tradição encontrada em Santa Olímpia faz parte de um projeto coletivo e, por isso, está em constante transformação. Dessa forma, a culinária envolve incorporações, adaptações e trocas sociais que fazem parte de um processo histórico, assumindo, a cada dia, novas formas de significados.

Na pesquisa, privilegiou-se o olhar para a mulher tirolesa do bairro de Santa Olímpia; no entanto, os homens atravessaram alguns momentos da pesquisa. Como por exemplo, durante a Festa da Polenta. Nela, a responsabilidade pela cozinha cabe a um homem, Sr. Correr (50 anos). Ele compartilha essa responsabilidade com Dona Pompermayer (87 anos).

Apesar de o Sr. Correr saber todas as receitas levantadas na pesquisa, as nonnas foram-me apresentadas como detentoras desse saber culinário do bairro. Esse detalhe talvez também revele as tradições trentino-tirolesas. São elas as guardiãs e responsáveis por alimentar as futuras gerações. Depois que nos deparamos com o conhecimento e a atuação de Sr. Correr, começamos a questionar: por que não haviam me apresentado-o antes para coletar as quantidades e as medidas das receitas? De algum modo, o autor foi direcionado para as incertezas do cotidiano e das medidas das receitas apresentadas pelas nonas.

O bairro de Santa Olímpia reivindica uma identidade cultural tirolesa a partir de vários fatores, como o dialeto, a religião, a música, o vestuário e, também, aquilo que se come, o modo como se come, onde e com quem se come. $\mathrm{O}$ ritual de reunir-se em volta da mesa e as festas no bairro contam, criam e transportam elementos da memória do bairro tirolês em Piracicaba. As tradições alimentares do bairro acumulam os dias difíceis enfrentados no passado e a fartura do presente. As receitas e tradições levantadas no processo de pesquisa revelam a identidade cultural tirolesa do bairro de Santa Olímpia.

\section{Consideraçóes finais}

A memória do processo de registro e documentação da culinária do bairro de Santa Olímpia, para elaboração do livro de receitas, se revelou como um campo de estudo privilegiado para o conhecimento antropológico. No processo de (re)construção de sua cultura, através das festas promovidas no bairro, os tiroleses reivindicam uma cultura "autentica". No entanto, ao indicarem como fonte de pesquisa as nonnas, os tiroleses demonstram que é no cotidiano que a memória coletiva é alimentada, vivida e testemunhada.

Inscritas no corpo e nos discursos das nonnas as receitas, que surgiram nas rodas de conversa, se revelaram como vetores de comunicação e sociabilidade de Santa Olímpia, uma vez que remontam 
os processos históricos de consolidação do bairro. Foi mostrando a participação das mulheres na superação dos dias difíceis da migração dos tiroleses para Piracicaba-SP que o processo de documentação e registro da culinária atuou na valorização de certa memória feminina do bairro de Santa Olímpia.

\section{Agradecimentos}

Ao Grupo de Pesquisas Visuais e Urbanas da Unifesp - Visurb.

\section{Referências}

1. Maciel ME. Uma cozinha à brasileira. Estudos Históricos 2004; (33):25-39.

2. Da Matta R. O que faz o Brasil, Brasil? Rio de Janeiro: Rocco; 1986. p. 22.

3. Maciel ME, Castro HC. A comida boa para pensar: sobre práticas, gostos e sistemas alimentares a partir de um olhar socioantropológico. Demetra 2013; 8(Supl.1):321-328.

4. Fischler C. L'Homnivore. Paris: Odile Jacob; 1990. p. 20.

5. Magnani JGC. Santana do Parnaíba: memória e cotidiano. In: Abreu R, Chagas MS, Santos MS, organizadores. Museus, coleções e patrimônios: narrativas polifônicas. Rio de Janeiro: Garamond Universitária; 2007. p. 40.

6. Camargo FM. Santa Olímpia e suas relações com a cidade de Piracicaba: memória e cotidiano de um bairro tirolês. Iluminuras 2013; 14(34):104-124.

7. Maciel ME. Cultura e alimentação ou o que têm a ver os macaquinhos de Koshima com BrillatSavarin? Horiz. Antropol. 2001; 7(16):145-46.

8. Amon D, Menasche R. Comida como narrativa da memória social. Sociedade e Cultura 2008; 11(1):13-21.

Recebido: $11 / 4 / 2015$

Revisado: $04 / 6 / 2015$

Aprovado: 09/7/2015 